\title{
Oral Lichen Planus in Thai Patients Has a Low Prevalence of Human Papillomavirus
}

\author{
Pratanporn Arirachakaran, ${ }^{1,2}$ Jira Chansaengroj, ${ }^{3}$ Woradee Lurchachaiwong, \\ Patnarin Kanjanabud, ${ }^{1}$ Kobkan Thongprasom, ${ }^{1,2}$ and Yong Poovorawan ${ }^{3}$ \\ ${ }^{1}$ Department of Oral Medicine, Faculty of Dentistry, Chulalongkorn University, Bangkok 10330, Thailand \\ ${ }^{2}$ Oral Diseases Unit, Faculty of Dentistry, Chulalongkorn University, Bangkok 10330, Thailand \\ ${ }^{3}$ Center of Excellence in Clinical Virology, Faculty of Medicine, Chulalongkorn University, Bangkok 10330, Thailand \\ Correspondence should be addressed to Pratanporn Arirachakaran; pratanporn.a@chula.ac.th
}

Received 17 April 2013; Accepted 8 May 2013

Academic Editors: C. Lekic, G. H. Sperber, and D. Wray

Copyright (C) 2013 Pratanporn Arirachakaran et al. This is an open access article distributed under the Creative Commons Attribution License, which permits unrestricted use, distribution, and reproduction in any medium, provided the original work is properly cited.

\begin{abstract}
Background. Oral lichen planus (OLP) is a common chronic inflammatory immune-mediated disease, with an etiopathogenesis associated with cell-mediated immunological dysfunction. Viral infection has been hypothesized as a predisposing factor in the pathogenesis of this disease. Viruses may alter host cell function by inducing the abnormal expression of cellular proteins leading to disease development. However, reports on the relationship between human papillomavirus (HPV) and OLP are inconclusive. Objective. To explore the association between HPV and OLP in Thai patients. Materials and Methods. DNA was extracted from thirty-seven fresh-frozen tissue biopsy specimens from OLP lesions, and polymerase chain reaction assay for the L1 and E1 genes covering 32 types of high- and low-risk HPV was performed. Results. HPV DNA was detected in one tissue biopsy from an atrophictype OLP lesion. All control samples were negative. Genomic sequencing of the E1 gene PCR product demonstrated that the HPVtype 16 found in the lesion is closely related to the East Asian type. Conclusion. Our data indicate a low prevalence of HPV infection in OLP lesions in Thai patients.
\end{abstract}

\section{Introduction}

Oral lichen planus (OLP) is a chronic inflammatory disease in which the immunopathogenesis involves cell-mediated immune dysregulation [1]. OLP affects $0.5-2.2 \%$ of the global population. However, prevalence varies according to geographic location [2]. This disease is commonly seen in Thai patients [3], with presentations ranging from symptom-free to a burning sensation or severe pain interfering with phonation, mastication, and deglutition [1].

OLP is classified as a potentially malignant disorder (PMD) of the oral mucosa with a transforming rate of $0-6.25 \%[1,4]$. Histologically, lesions are characterized by hyperkeratosis, basal layer liquefaction of the oral epithelium-connective tissue interface, and a dense infiltration of a band of lymphocytes $[5,6]$. Unidentified antigen presented to lymphocytic cells may play a role in this disease. Previous studies suggest that OLP is a T-cell-mediated inflammatory disease in which autocytotoxic $\mathrm{CD} 8^{+} \mathrm{T}$ cells trigger apoptosis in oral epithelial cells [1]. Exogenous agents may also alter keratinocyte antigen expression. The response of these specific $\mathrm{CD}^{+} \mathrm{T}$ cells is similar to what occurs during a viral infection where a virus can act as a cytoplasmic antigen or induce the expression of host cell proteins, resulting in an altered host cell protein profile [7]. Therefore, it is of interest to investigate the possibility of viral involvement in the pathogenesis of OLP.

Human papillomaviruses (HPVs) are epitheliotropic DNA viruses with more than 150 genotypes. Clinically, HPV infection is usually characterized by hyperplastic, papillomatous, or verrucous lesions in the stratified epithelium. HPV classification has been based on the degree of HPV DNA homology. HPV has been detected in various types of oral lesions, ranging from benign to malignant $[8,9]$. HPV typing can be valuable as a predictor of disease progression. Approximately 40 types are known to infect the oral cavity and 
urogenital tract [10]. HPVs are divided into high and low oncogenic risk groups [11]. HPV types $2,3,6,11,13,16,18,31$, $33,35,45,52$, and 57 are classified as high-risk (HR) types and reported to be associated with malignancy [11]. Twenty-four low-risk (LR) HPV genotypes (HPV 1, 2, 3, 4, 6, 7, 10, 11, 13, $16,18,30,31,32,33,35,45,52,55,57,59,69,72$, and 73) are associated with benign lesions such as papilloma and condyloma $[10,12]$. HPV16 and HPV18 have increasingly been reported as being associated with $\mathrm{PMD}$, and oral squamous cell carcinoma (OSCC) [13-17]. A meta-analysis including data from the years 1966-2010 reported that in comparison with normal mucosa, HPV was detected 2-3 fold more frequently in PMD and OSCC [9].

A causal role of HPV has been reported for OLP and OSCC, but there are wide variations in disease prevalence with regard to different geographic populations $[1,18]$. Furthermore, data obtained from the International biological study of cervical cancer (IBSCC) showed phylogenetic clusters of HPV-16 sequence variants in direct relation to specific racial groups and geographic locations [19].

Most HPV infections are asymptomatic; however, lesions can develop any time after infection. Currently, there is no clear understanding of HPV latency, reactivation, or subclinical infection without apparent disease [20]. The course of $\mathrm{HPV}$ infection is dependent on the subtype and associated cofactors such as smoking, nutritional status, immune status, and hormonal influence [8].

The aims of this study were to investigate the presence of HPV DNA in OLP lesions of Thai patients using PCR and to characterize the virus type in those lesions by nucleotide sequencing.

\section{Materials and Methods}

2.1. Sample Collection. Participants with a clinical diagnosis of OLP who visited the Department of Oral Medicine, Faculty of Dentistry, Chulalongkorn University from November 2008 to August 2010 were recruited into the study. Prior to enrollment, the patients signed informed consent forms approved by the Ethics Committee of the Faculty of Dentistry. None of the participants received any medication for their OLP before specimens were obtained. Specimens were collected from tissue biopsies for histopathological examination. Thirty-seven cases that were confirmed as OLP positive based on histopathological evaluation were selected for DNA extraction. Each specimen was transferred to a $1.5 \mathrm{~mL}$ sterile microcentrifuge tube containing $0.5 \mathrm{~mL}$ of virus transport media. Matching controls from each subject were obtained by scraping healthy normal mucosa into a $1.5 \mathrm{~mL}$ sterile microcentrifuge tube containing virus transport media. All samples were kept on ice, immediately taken to the laboratory, and stored at $-80^{\circ} \mathrm{C}$ until further analysis.

2.2. DNA Extraction, HPV Amplification and Sequencing. DNA extraction and purification from both tissue biopsies and negative control cells were performed using the Qiamp DNA mini kit (QIAGEN, Valencia, CA) per the manufacturer's instructions. DNA extraction from control sites was performed by standard organic extraction (phenol-chloroform) and alcohol precipitation. Purified DNA was re-suspended in deionized water to a final volume of $30 \mu \mathrm{L}$.

We assayed for HPV DNA using primers to both the E1 and L1 regions. The primer design, amplification, and sequencing were performed [21]. Briefly, the first round PCR was performed using HPV-E1F1_1219 (nt 1160-1183) sequences; 5 '-AGTACAGGTTCTAAAACGAAAGT-3' and HPVE1R1_2119 (nt 2076-2100) 5'-CATTATCAAATGCCCAYTGYACCAT- $3^{\prime}$. These primers yield a PCR product of $940 \mathrm{bp}$. The second round PCR was performed using $1 \mu \mathrm{L}$ of product from the first round as template and HPV-E1F2_1383 (nt 1315-1335) sequences; 5' -GCGAAGACAGCGGNTATGGC-3' and HPV-E1R1_2119 as primers. These primers yield a PCR product of $785 \mathrm{bp}$. The use of these consensus primers allowed the amplification of a broad spectrum of HPV-type DNA. The MY09/MY11 and GP5+/GP6+ primer sets are the most widely used in detecting the HPV L1 gene region. The house keeping $\beta$-globin gene was used as an internal control. The PCR products were subjected to $2 \%$ agarose gel (FMC Bio-products Rockland, ME) electrophoresis, and appropriately sized bands were purified using the HiYield Gel/PCR DNA Fragments Extraction kit (Bioscience). The purified DNA fragments were sequenced by FirstBASE Laboratories SDNBHD (Selangor Darul Ehsan, Malaysia) and were analyzed using the BLAST analysis tool in the NCBI database (http://blast.ncbi.nlm.nih.gov/Blast.cgi).

2.3. Phylogenetic Tree Construction. The sequences were aligned with the BioEdit program (version 7.0.4.1). The phylogenetic trees were constructed using the MEGA4 program with neighbor-joining analysis, and Bootstrapping applied with 1,000 replicates was used to support tree topologies.

\section{Results}

The study comprised 37 participants, ranging from 19-78 years old, with a median and mean age of 48 and $49( \pm 12.58)$ years, respectively. The male to female ratio was $12: 25$. The 37 specimens were obtained from 12 hyperplastic-, 23 atrophic-, and 2 ulcerative-type OLP lesions. All subjects had lesions on both the buccal mucosa and gingiva at the time of biopsy. All specimens from the tissue biopsies had a confirmed diagnosis of OLP (Figure 1). HPV DNA was detected in one of the specimens $(2.7 \%)$, and the PCR result of the positive sample is shown in Figure 2. The HPV DNA positive sample came from an atrophic-type OLP lesion. None of the control samples obtained by scraping is tested positive for HPV DNA. The result of the BLAST analysis of the positive specimen showed a $100 \%$ homology to HPV16. The phylogenetic tree constructed with HPV 16 indicated that this virus was related to the East Asian variants (Figure 3). The accession number of the submitted sequence is JF944819.

\section{Discussion}

OLP affects $1.27 \%$ of the global population with a prevalence varying according to geographic locations [2]. OLP 


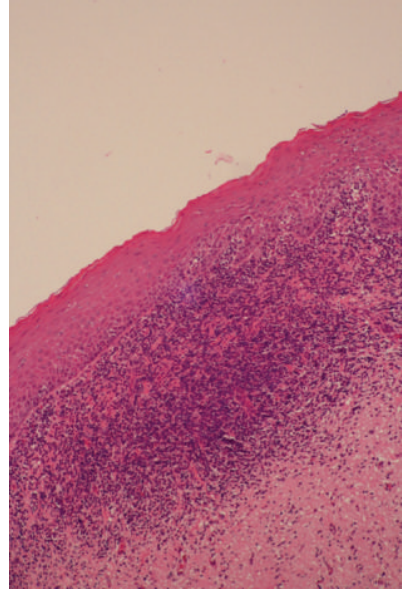

(a)

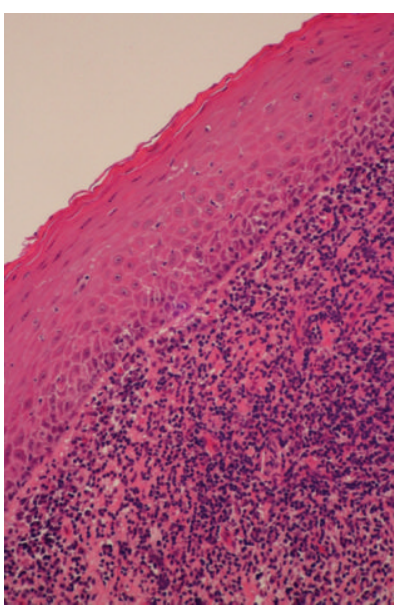

(b)
FIgURE 1: Histopathology of tissue biopsies confirming oral lichen planus. (a) Magnification $\times 100$ shows hyperkeratosis, a bandlike of lymphocytes infiltrate in the superficial lamina propria, and (b) magnification $\times 200$ shows degeneration of basal cell layer, various degrees of parakeratosis, and orthokeratosis of the surface epithelium, dense infiltrate of lymphocytes subjacent to the epithelium, and degenerating keratinocytes.

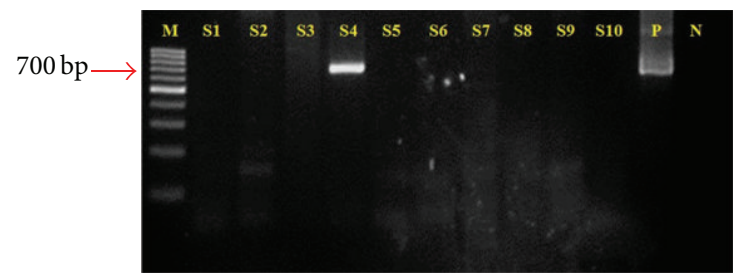

Figure 2: Agarose gel electrophoresis result of human papillomavirus E1 nested PCR detection. M: Marker, DNA ladder (Fermentas), S: sample, P: positive control, and N: negative control. DNA band in $\mathrm{S} 4$ indicates the sample with positive result.

predominantly affects middle-aged women between 30-60 years old [1]. In the present study, HPV DNA was found in an oral lesion of a 72-year-old female who presented to the oral medicine clinic complaining of a burning sensation in the oral cavity for one month prior to seeking treatment. Clinical examination revealed lesions suggestive of OLP on both the left and right buccal mucosa and her marginal gingiva. Biopsy was taken from the right buccal mucosa, and a histopathological evaluation confirmed the diagnosis of OLP and excluding malignancy.

The present study supports the finding of a previous report on HPV prevalence in OLP in Thai patients. A prior study in Thai patients did not find HPV in any of the sixteen OLP lesions examined [22], while in the current study HPV was detected in only one of the 37 fresh tissue biopsies, indicating a low prevalence of $2.7 \%$. Due to the very low prevalence of HPV in OLP lesions found in the present study, we were limited in our ability to analyze confounding risk factors such as age, sex, sexual habits, history of smoking, and alcohol consuming for OLP.
A systematic review shows a statistically significant twofold difference (11\% versus $23 \%$ ) between HPV associated with OLP lesions and HPV found in normal tissue [9]. Among studies with positive results, there was a high degree of variation in experimental methods, ranging from differences in selection criteria and specimen collection, to methods of detection that affect the sensitivity and specificity of each study $[9,13-15,18,23-26]$.

The in vitro study of HPV is difficult since HPV cannot be grown using conventional cell culture methods, requiring other techniques. The choice of analysis technique used is also important. Kellokoski et al. [27] reported analyzing healthy oral mucosa for HPV DNA using dot blot hybridization, and polymerase chain reaction (PCR) resulted in positive findings in $3.8 \%$ and $29.4 \%$ of samples, respectively. PCR is considered to be a very sensitive detection method. In the present study, PCR was used to amplify and detect HPV DNA target sequences from fresh tissue samples by using consensus primers targeting conserved regions of the HPV genome. Such primers allow the amplification of a broad spectrum of HPV-type DNA. Although PCR amplification of the SPF10 (L1) gene is widely used in commercially available test kits, we also selected primers from the E1 gene, designed to cover 32 of the HPV DNA genotypes including HPV 6, 11, 16, 18 among other low- and high-risk HPVs (HPV 6, 11, 16, 18, 30, 31, 32, 33, $34,35,39,40,42,44,51,52,53,55,56,58,59,66,68,70,71,73$, $74,81,82,85,90,91)$ [21]. PCR amplification with primers designed for early gene (E) regions is reported to be very sensitive and efficient $[23,28]$. The E1 gene encodes functional proteins essential for viral replication and is a gene now used in a commercial product for classifying HPV genotypes (Papillo-Check, Frickenhausen, Germany). The E1 PCR assay can be used for HPV detection with a sensitivity of $10^{2}$ copies $\mu \mathrm{L}^{-1}$ and also allows an accurate identification since it can amplify long nucleotide sequences [21].

Efforts in exploring the correlation between HPV and OLP have mainly focused on epidemiological studies of different populations. It is noteworthy that there have been profound variations in the results found among geographically different populations [1]. Studies in the USA using in situ hybridization on paraffin embedded specimens did not find any relationship between HPV and OLP $[29,30]$. In contrast, patients with OLP in European countries are reported to have HPV prevalences ranging from $11.8 \%$ to $100 \%$ [9, 13, 15, 2326]. Currently, twenty-four HPV types have been detected in oral PMD and OSCC. Notably, the most common type present in OSCC was HPV 16, at a prevalence of $16 \%[9,17$, $31,32]$. Previous reports on HPV prevalence in OLP showed HPV types $6,11,16,18,31,32,33,39$, or 55 present with the majority identified as type 6,11 , or $16[9,13,14,18,24,33]$. A longitudinal study by Nielsen et al. [34] reported $40.8 \%$ of OLP lesions were HPV positive versus none in normal mucosa. The OLP cases that developed OSCC within 4-12 years were positive for HPV.

The DNA sequence of the HPV found in the present study was identified as the high-risk-type 16. The lesion positive for HPV DNA was of the atrophic type. Mattila et al. [33] reported finding HPV DNA in $15.9 \%$ of atrophic OLP lesions. Moreover, 5 out of 13 atrophic OLP samples with HPV 


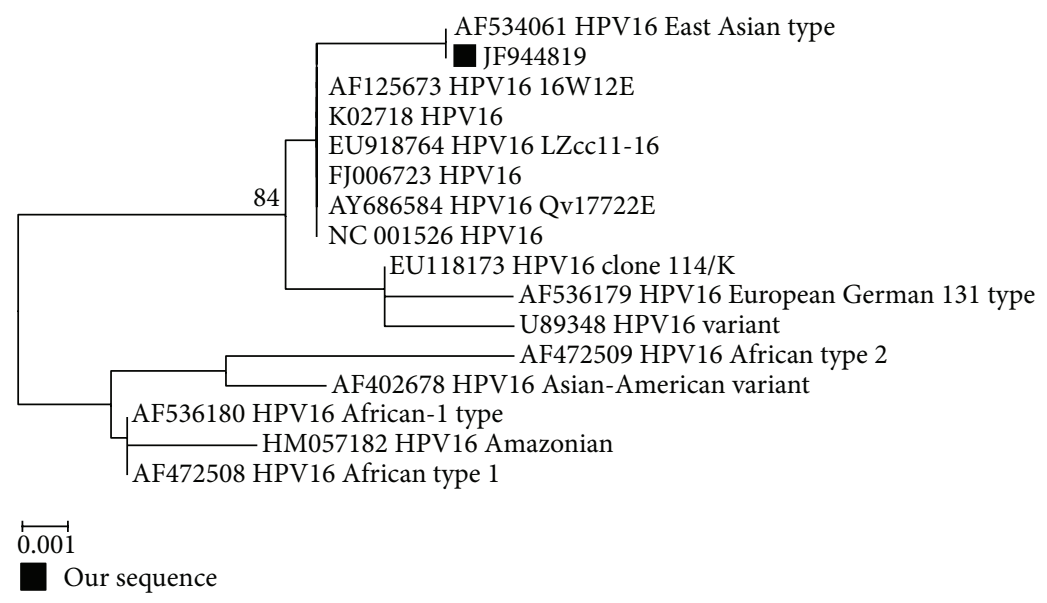

FIGURE 3: Phylogenetic tree in E1 region of HPV16 variants.

infection developed cancer. Among those five, three were infected by HR-HPV: types 16 and 33, and two were positive for types 6 and 11, which are LR-HPV.

A predisposition of the oropharyngeal mucosa to malignant transformation by HPV was first suggested when HPV16 was detected in tumors of the tongue, tonsil, and pharynx but not in control tissues [35]. Furthermore, a large retrospective study of oropharyngeal cancer by Gillison et al. [36], indicated that poorly differentiated tumors were more likely to be HPV positive than well-differentiated and moderately differentiated tumors. A long-term followup is needed to determine if the aggressive behavior of HPV-infected OLP is associated with HR or LR type of HPV in malignant transformation. The HPV-type 16 sequence variation found from a Thai patient with OLP in the current study was phylogenetically classified as an East Asian type which originated from European variant [37]. Existing data on HPV sequence variation are mostly from studies of genital HPV [29] and oropharyngeal cancer [36]. Some investigations have proposed that HPV16 variants are associated with virus behavior including virus assembly, viral persistence, an increase in the risk of cancer invasiveness, and effect on the host immune response [19, 36, 38-41]. However, the distribution of the virus variants was also suggested to possibly be a simple reflection of the populations studied. Currently, data on sequence variation and characterization of HPV behavior from infected oral tissues is still very limited. Sequencing HPV DNA may be a valuable tool in predicting the aggressiveness of a premalignant lesion. Further studies that aimed at exploring the putative link between geographic location and HPV in OLP may reveal interesting findings. A prospective study of OLP with and without HPV DNA may show differences in disease progression of this potentially malignant disorder.

\section{Conclusion}

OLP is an inflammatory immune-mediated disease associated with cell-mediated immunological dysfunction. Infectious agents have been proposed as one of the causes of OLP.
Our data showed a low prevalence of HPV infection in OLP lesions. We conclude that HPV may not play a significant role in Thai patients with OLP. Genomic sequencing of the E1 gene demonstrated that the HPV-type 16 from the sole positive lesion was closely related to the East Asian type. Although it is likely that additional factors affect malignant transformation, identifying these will require the long-term followup of HPVpositive OLP patients.

\section{Acknowledgments}

This study was supported by the Thailand Research Fund MRG5280047, Center of Excellence in Clinical Virology, Department of Pediatrics, Faculty of Medicine, Chulalongkorn University, Chulalongkorn Memorial Hospital, Outstanding Professor Fund, Thailand Research Fund and The Higher Education Research Promotion, and National Research University Project of Thailand, Office of the Higher Education Commission (HR1155A). This study was conducted according to the ethical standards of the World Health Organizations Declaration of Helsinki (version 2002), and the study protocols were reviewed and approved by the Ethics Committee of the Faculty of Dentistry, Chulalongkorn University, reference no. 86/2008 with the understanding and with signed informed consent of the patients involved. The authors thank Dr. Pairoj Junyangdikul, for providing laboratory instruments. They would like to thank Associate Professor Kittipong Dhanuthai for the histopathology confirmation and Dr. Klawajee Kaetkaew and the staff at the Department of Oral Medicine for their assistance. The authors would like to express their gratitude to Dr. Kevin Tompkins for his critical editing.

\section{References}

[1] G. Lodi, C. Scully, M. Carrozzo, M. Griffiths, P. B. Sugerman, and K. Thongprasom, "Current controversies in oral lichen planus: report of an international consensus meeting-part 1: viral infections and etiopathogenesis," Oral Surgery, Oral 
Medicine, Oral Pathology, Oral Radiology and Endodontology, vol. 100, no. 1, pp. 40-51, 2005.

[2] B. E. McCartan and C. M. Healy, "The reported prevalence of oral lichen planus: a review and critique," Journal of Oral Pathology and Medicine, vol. 37, no. 8, pp. 447-453, 2008.

[3] K. Thongprasom, P. Youngnak-Piboonratanakit, S. Pongsiriwet, T. Laothumthut, P. Kanjanabud, and L. Rutchakitprakarn, "A multicenter study of oral lichen planus in Thai patients," Journal of Investigative and Clinical Dentistry, vol. 1, no. 1, pp. 29-36, 2010.

[4] M. Gorsky and J. B. Epstein, "Oral lichen planus: malignant transformation and human papilloma virus: a review of potential clinical implications," Oral Surgery, Oral Medicine, Oral Pathology, Oral Radiology and Endodontology, vol. 111, no. 4, pp. 461-464, 2011.

[5] M. H. Thornhill, "Immune mechanisms in oral lichen planus," Acta Odontologica Scandinavica, vol. 59, no. 3, pp. 174-177, 2001.

[6] I. Al-Hashimi, M. Schifter, P. B. Lockhart et al., "Oral lichen planus and oral lichenoid lesions: diagnostic and therapeutic considerations," Oral Surgery, Oral Medicine, Oral Pathology, Oral Radiology and Endodontology, vol. 103, pp. S25.e1-S25.e12, 2007.

[7] A. K. Abbas and A. H. Lichtman, "Immunity to microbes," in Cellular and Molecular Immunology, chapter 15, pp. 345-366, WB Saunders, Philadelphia, Pa, USA, 5th edition, 2004.

[8] J. Rautava and S. Syrjänen, "Human papillomavirus infections in the oral mucosa," Journal of the American Dental Association, vol. 14, pp. 905-914, 2011.

[9] S. M. Syrjänen, G. Lodi, I. von Bültzingslöwen et al., "Human papillomaviruses in oral carcinoma and oral potentially malignant disorders: a systematic review," Oral Diseases, vol. 17, supplement 1, pp. 58-72, 2011.

[10] A. Marini, M. Wagenmann, E. Ting, and U. R. Hengge, "Squamous cell cancer and human papillomavirus infection in oral lichen planus: case report and literature review," Dermatologic Surgery, vol. 33, no. 6, pp. 756-760, 2007.

[11] H. zur Hausen, "Papillomaviruses and cancer: from basic studies to clinical application," Nature Reviews Cancer, vol. 2, no. 5, pp. 342-350, 2002.

[12] S. Syrjänen and K. Syrjänen, "HPV infections of the oralmucosa," in Papillomavirus Infections in Human Pathology, K. Syrjänen and S. Syrjänen, Eds., chapter 17, pp. 379-412, John Wiley \& Sons, New York, NY, USA, 2000.

[13] M. Jontell, S. Watts, M. Wallstrom, L. Levin, and K. Sloberg, "Human papilloma virus in erosive oral lichen planus," Journal of Oral Pathology and Medicine, vol. 19, no. 6, pp. 273-277, 1990.

[14] G. Campisi, L. Giovannelli, P. Aricò et al., "HPV DNA in clinically different variants of oral leukoplakia and lichen planus," Oral Surgery, Oral Medicine, Oral Pathology, Oral Radiology and Endodontology, vol. 98, no. 6, pp. 705-711, 2004.

[15] L. Giovannelli, G. Campisi, G. Colella et al., "Brushing of oral mucosa for diagnosis of HPV infection in patients with potentially malignant and malignant oral lesions," Molecular Diagnosis and Therapy, vol. 10, no. 1, pp. 49-55, 2006.

[16] V. E. Furrer, M. B. Benitez, M. Furnes, H. E. Lanfranchi, and N. M. Modesti, "Biopsy versus superficial scraping: Detection of human papillomavirus $6,11,16$, and 18 in potentially malignant and malignant oral lesions," Journal of Oral Pathology and Medicine, vol. 35, no. 6, pp. 338-344, 2006.

[17] D. J. Adelstein, J. A. Ridge, M. L. Gillison et al., "Head and neck squamous cell cancer and the human papillomavirus: summary of a national cancer institute state of the science meeting, November 9-10, 2008, Washington, D.C.," Head \& Neck, vol. 31, no. 11, pp. 1393-1422, 2009.

[18] K. Szarka, I. Tar, E. Fehér et al., "Progressive increase of human papillomavirus carriage rates in potentially malignant and malignant oral disorders with increasing malignant potential," Oral Microbiology and Immunology, vol. 24, no. 4, pp. 314-318, 2009.

[19] T. Yamada, M. M. Manos, J. Peto et al., "Human papillomavirus type 16 sequence variation in cervical cancers: a worldwide perspective," Journal of Virology, vol. 71, no. 3, pp. 2463-2472, 1997.

[20] F. Stubenrauch and L. A. Laimins, "Human papillomavirus life cycle: active and latent phases," Seminars in Cancer Biology, vol. 9, no. 6, pp. 379-386, 1999.

[21] W. Lurchachaiwong, P. Junyangdikul, S. Payungporn et al., "Human papillomavirus genotypes among infected Thai women with different cytological findings by analysis of E1 genes," New Microbiologica, vol. 34, no. 2, pp. 147-156, 2011.

[22] S. P. Khovidhunkit, W. Buajeeb, S. Sanguansin, S. Poomsawat, and W. Weerapradist, "Detection of human papillomavirus in oral squamous cell carcinoma, leukoplakia and lichen planus in Thai patients," Asian Pacific Journal of Cancer Prevention, vol. 9, no. 4, pp. 771-775, 2008.

[23] N. J. Maitland, T. Bromidge, M. F. Cox, I. J. Crane, S. S. Prime, and C. Scully, "Detection of human papillomavirus genes in human oral tissue biopsies and cultures by polymerase chain reaction," The British Journal of Cancer, vol. 59, no. 5, pp. 698703, 1989 .

[24] M. Cox, N. Maitland, and C. Scully, "Human herpes simplex1 and papillomavirus type 16 homologous DNA sequences in normal, potentially malignant and malignant oral mucosa," European Journal of Cancer Part B: Oral Oncology, vol. 29, no. 3, pp. 215-219, 1993.

[25] M. A. González-Moles, A. Rodríguez-Archilla, I. Ruiz Avila, F. Esteban, S. González-Moles, and M. Bravo, "Presence of HPV 16 sequences in oral lichen planus lesions.", Bulletin du Groupement International pour la Recherche Scientifique en Stomatologie \& Odontologie, vol. 40, no. 2-3, pp. 92-97, 1998.

[26] L. Sand, J. Jalouli, P. A. Larsson, and J. M. Hirsch, "Human papilloma viruses in oral lesions," Anticancer Research, vol. 20, no. 2 B, pp. 1183-1188, 2000.

[27] J. K. Kellokoski, S. M. Syrjänen, F. Chang, M. Yliskoski, and K. J. Syrjänen, "Southern blot hybridization and PCR in detection of oral human papillomavirus (HPV) infections in women with genital HPV infections," Journal of Oral Pathology and Medicine, vol. 21, no. 10, pp. 459-464, 1992.

[28] C. Ostwald, P. Muller, M. Barten et al., "Human papillomavirus DNA in oral squamous cell carcinomas and normal mucosa," Journal of Oral Pathology and Medicine, vol. 23, no. 5, pp. 220225, 1994.

[29] S. K. Young and K. W. Min, "In situ DNA hybridization analysis of oral papillomas, leukoplakias, and carcinomas for human papillomavirus," Oral Surgery Oral Medicine and Oral Pathology, vol. 71, no. 6, pp. 726-729, 1991.

[30] C. S. Miller, D. K. White, and D. D. Royse, "In situ hybridization analysis of human papillomavirus in orofacial lesions using a consensus biotinylated probe," The American Journal of Dermatopathology, vol. 15, no. 3, pp. 256-259, 1993.

[31] A. R. Kreimer, G. M. Clifford, P. Boyle, and S. Franceschi, "Human papillomavirus types in head and neck squamous cell carcinomas worldwide: a systemic review," Cancer Epidemiology Biomarkers and Prevention, vol. 14, no. 2, pp. 467-475, 2005. 
[32] A. R. Kreimer, R. K. Bhatia, A. L. Messeguer, P. González, R. Herrero, and A. R. Giuliano, "Oral human papillomavirus in healthy individuals: a systematic review of the literature," Sexually Transmitted Diseases, vol. 37, no. 6, pp. 386-391, 2010.

[33] R. Mattila, J. Rautava, and S. Syrjänen, "Human papillomavirus in oral atrophic lichen planus lesions," Oral Oncology, vol. 48, no. 10, pp. 980-984, 2012.

[34] H. Nielsen, B. Norrild, P. Vedtofte, F. Prætorius, J. Reibel, and P. Holmstrup, "Human papillomavirus in oral premalignant lesions," European Journal of Cancer B, vol. 32, no. 4, pp. 264270, 1996.

[35] J. L. Brandsma and A. L. Abramson, "Association of papillomavirus with cancers of the head and neck," Archives of Otolaryngology - Head and Neck Surgery, vol. 115, no. 5, pp. 621625, 1989.

[36] M. L. Gillison, W. M. Koch, R. B. Capone et al., "Evidence for a causal association between human papillomavirus and a subset of head and neck cancers," Journal of the National Cancer Institute, vol. 92, no. 9, pp. 709-720, 2000.

[37] I. Cornet, T. Gheit, M. R. Iannacone et al., "HPV16 genetic variation and the development of cervical cancer worldwide," The British Journal of Cancer, vol. 108, no. 1, pp. 240-244, 2013.

[38] R. Kirnbauer, J. Taub, H. Greenstone et al., "Efficient selfassembly of human papillomavirus type $16 \mathrm{~L} 1$ and L1-L2 into virus-like particles," Journal of Virology, vol. 67, no. 12, pp. 69296936, 1993.

[39] L. F. Xi, G. W. Demers, L. A. Koutsky et al., "Analysis of human papillomavirus type 16 variants indicates establishment of persistent infection," Journal of Infectious Diseases, vol. 172, no. 3, pp. 747-755, 1995.

[40] P. Londesborough, H. O. Linda, G. Terry, J. Cuzick, C. Wheeler, and A. Singer, "Human papillomavirus genotype as a predictor of persistence and development of high-grade lesions in women with minor cervical abnormalities," International Journal of Cancer, vol. 69, no. 5, pp. 364-368, 1996.

[41] M. C. Stöppler, K. Ching, H. Stöppler, K. Clancy, R. Schlegel, and J. Icenogle, "Natural variants of the human papillomavirus type 16 E6 protein differ in their abilities to alter keratinocyte differentiation and to induce p53 degradation," Journal of Virology, vol. 70, no. 10, pp. 6987-6993, 1996. 


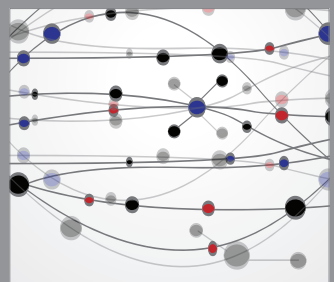

The Scientific World Journal
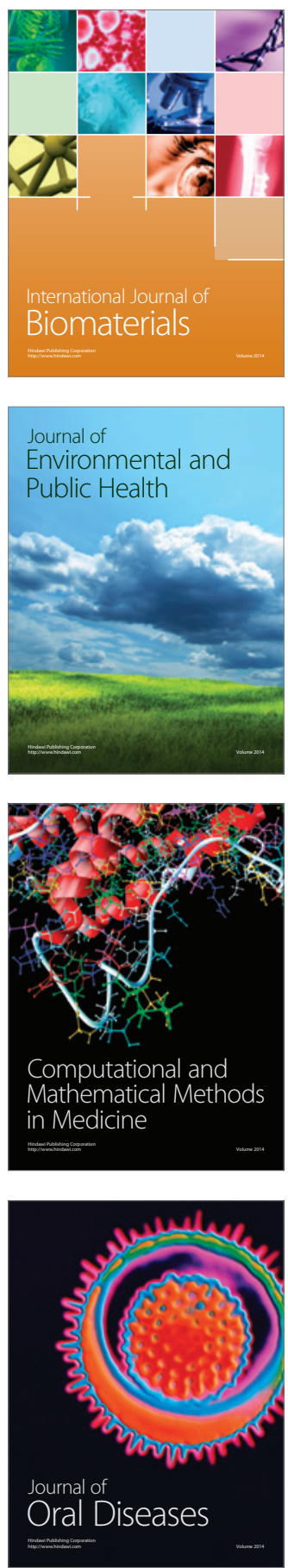
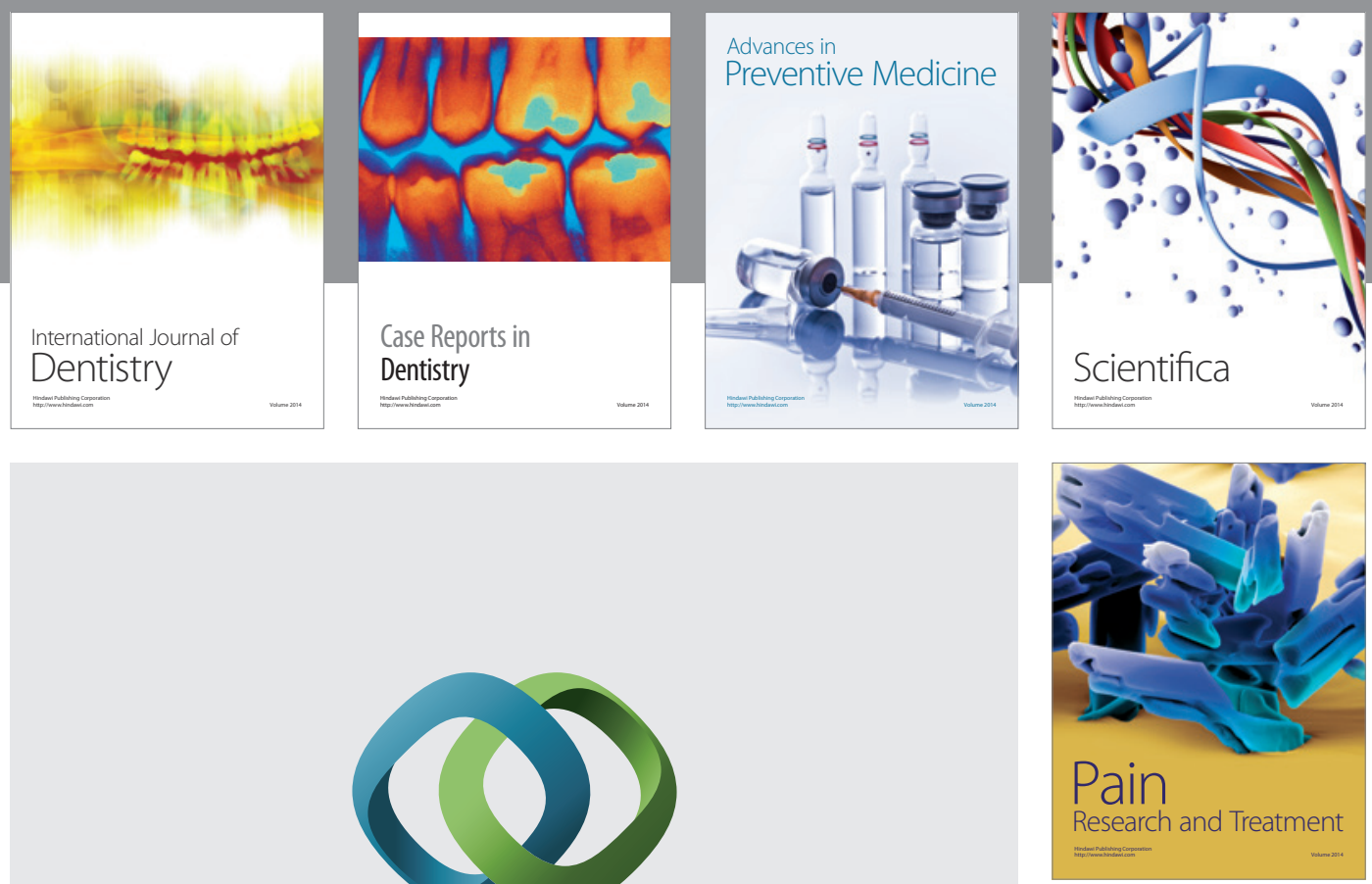

\section{Hindawi}

Submit your manuscripts at

http://www.hindawi.com
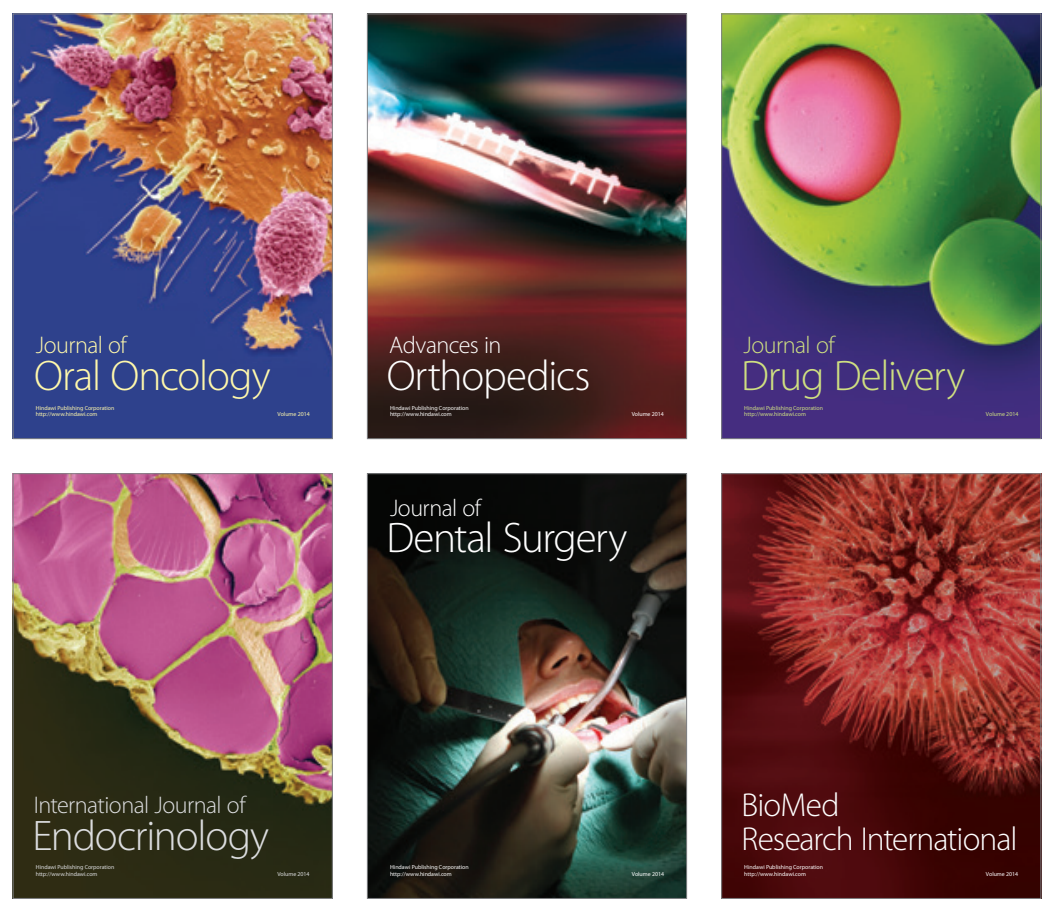

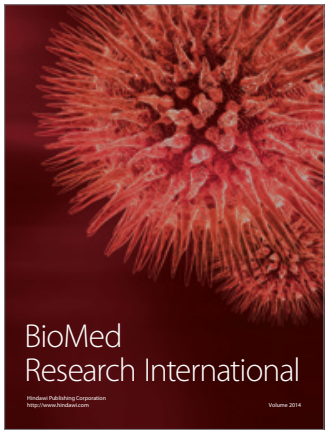

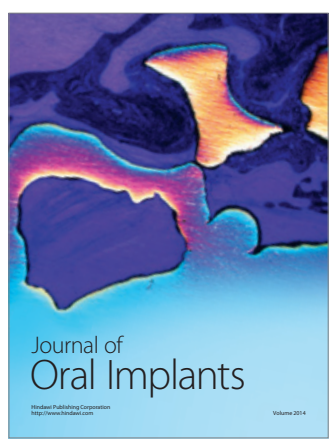
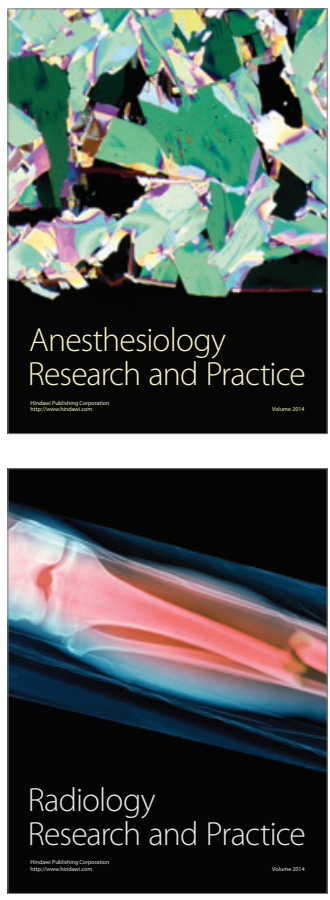